\title{
Effective Student Practices and Their Contribution to Formation of Students
}

M. Smidova (Maria Smidova)

Department of Family Science, Faculty of Theology, Trnava University

Original Article in Trnava, SK

\section{E-mail address:}

mariasmidova@hotmail.com

\section{Reprint address:}

Maria Smidova

Department of Family Science

Faculty of Theology

Trnava University in Trnava

Kostolna 1

P.O.Box 173

81499 Bratislava

SK

Source: Clinical Social Work and Health Intervention

Pages: $114-118$

Volume: 9

Cited references: 4

\section{Reviewers:}

Vlastimil Kozon

Allgemeines Krankenhaus - Medizinischer Universitätscampus, Vienna, AT

Roberto Cauda

University Catholica Clinica, Gemeli, Rome, IT

\section{Key words:}

Counseling. Social Workers' skills. Communication training. Effective practices.

\section{Publisher:}

International Society of Applied Preventive Medicine i-gap

CSWHI 2018; 9(2): 114 - 118; DOI 10.22359/cswhi_9_2_17 @ 2018 Clinical Social Work and Health Intervention

\section{Abstract:}

Starting a new model of effective student practices using counseling in families with specific social problems, we planned to deal with the examination, verification and description of the counseling method. 
How do we perceive counseling? Its main competences are empathy and ethical reception. Other competencies include ability to identify the specificities of the conversation using multicultural competencies; engagement of positive psychology and overcoming the negative tone in theory and practice of counseling; finding more about conversation methods; crisis counseling practice; as well as anticipation of client's responses.

\section{Introduction}

In this paper, we focus on research we have conducted in order to verify the newly-formed method of Social Work. It is called counseling; in Slovakia, it is more known as "accompaniment". It is a method that helps to cope with difficult situations affecting an individual on personal, social and spiritual levels. Application of this method is relevant in all areas of human life. The essence of this new method is to promote people's capacities to help themselves; to lead them to selfhelp. This means to mobilize person's inner strength to solve a particular life situation on her/his own. The research refers to preparation and implementation of multi-day meetings of teachers, lecturers, students - volunteers and clients. The aim of these meetings is to create an atmosphere of safety and comfort, where the participants pass on their experience resulting from mutual communication. They spend several days actively together finding out more about their abilities, needs and skills. (Trebski, 2016)

\section{Research Definition}

The Effective Practice Model was based on an experiential learning where students go through different situations and then talk about them; evaluate them; receive an explanation of correct behavior. Meeting new people with special needs in an environment which allows them to spend several days together represented a new dimension of understanding of disability issues and other matters that such a state means for disabled person and her/his family.

\section{Research Problem and Objectives}

The research question was aimed at evaluating the accomplishment of objectives of the Effective Practices Model stated prior to the implementation of the pilot project. In the research, we wanted to find out to what extent the project participants perceived them as present and accomplished.

The main objective was to analyse the perception of the effective student practices application by its participants. Other research objectives:

1. The atmosphere of safety and comfort for students and clients of the Practice.

2. Promotion and professional and personal coaching of students while accomplishing assigned tasks.

3. Gaining new skills concerning the work of Social Workers with specific group of clients (especially training of communication between students and clients).

4. Gaining personal experience, meeting a new group of people and situations.

The research was exploratory in nature and therefore we have selected the following research questions:

1. What were the participants' expectations of the effective practice?

2. Whether, to what extent and based on what did the participants feel the atmosphere of safety and comfort during the meeting?

3. Whether, to what extent and based on what did the participants feel during the 
meeting support and the professional and personal guidance while completing assigned tasks?

4. Whether, to what extent and based on what did the participants acquire new skills related to the Profession of Social Workers with a specific group of clients?

5. Whether, to what extent and based on what did the participants acquire personal experience, meet a new group of people and experience new situations?

\section{Research Methodology}

This qualitative research was aimed at exploring the all-over benefit of the Effective Practices Model for individual participants. Research was exploratory in nature, since the main variable has not been empirically verified. With the questionnaire, we tried to define the assessments of certain areas that we have set as objectives of these events. In the questionnaire, we first asked participants to evaluate the level of accomplishment or satisfaction with completing a given objective, and then we asked them for explanation of their evaluation. It served as a tool helping participants to think deeper about their statement.

\subsection{Sample and Data Collection}

The sampling was controlled, based on the participants' attendance at the Effective Practices Study. The sample included families, students, teachers and guests (Breakwell et al. 2012).

\subsection{Data Analysis}

For this qualitative research, we chose the data categorization method, known as the CQR-m (Hill et al., 2005). It was a consensual qualitative research for simple qualitative data. The analysis consisted of creation of domains and categories; creation of a coding system; review of domains; subsequent categorization of answers. This part was done by two researchers who were creating domains and categories by themselves, and subsequently were looking for consensus in their arguments. The auditor was the last person evaluating their work from an outside perspective, or resolving disagreements in consensus. Several categories were created in the text, presented with relevant quotations from statements that clarified denotation of categories. Data analysis consisted of coded data. This analysis was done by two researchers independently. They met afterward trying to find consensus in coding. The result was a common version. This process included three following stages: creation of domains; main ideas; cross-analysis. Domains were keywords or phrases and based on them groups of responses were created. These domains were created based on responses categorization. At the main ideas stage, repeating words were eliminated from the data; the terms were simplified but without courageous paraphrasing.

\section{Discussion}

The research results suggest that effective student practices as one of several forms of counseling skills training are eligible. Teachers prepared this pilot project as a way to a better preparation of students for specific practical assistance in their future careers. The aim was to combine theory which represented a new method of Social Work with practical training in an authentic setting. During this Practice it was necessary to deepen the knowledge of a new target group, namely people with special needs and their families in the most natural environment. Research was examining the effectiveness of assistance to these clients. (Binarova M., Sobotkova I., 2007). This represents a new dimension of understanding of disability issues and everything else that such a state means for a disabled person and her/his family. 
This objective was met; participating students verified theoretical knowledge directly through the contact with such clients. At the same time, they were able to see these people in their natural environment in which they live; in their family. The presence of parents and other siblings during this stay created a true picture of the quality of life and relationship links between family members.

Students' expectations resulting from their motivation to enrich their understanding with new practical experiences that could help them to become acquainted with a new client with whom they had no prior experience were fulfilled. It was interesting for them to see the life of people who despite their disadvantage lived a positive life. Students were also able to test their skills in Practice. It was also essential for students to create an environment of peace and friendship to participating families. Acquired experience has created a new positive effect for students, specifically finding self-dignity arising from personal experience that their service was meaningful.

A very significant and positive effect of the practice was the feeling of reassurance that was formed based on a proper understanding of roles and safety resulting from the fact that students had the opportunity to consult all the problematic situations with the teachers. A feeling of imminent acceptance was perceived by students during informal communication. Openness and trust in communication was manifested through the possibility to express their feelings both positive and negative without fear that their opinion will not be correct or accepted.

This reinforces one of the main tools of counseling - communication. Students did not perceive the practice as a counseling training, but understood through experience what its main tool is. It was confirmed that counseling is a specialized help which includes relationship of equal value whereby the Professional has competency and qualification and communicates this equally with the client. The approach towards clients is better because of the example perceived during the Practice by teachers, i.e. teaching through personal example.

Understanding of particular situations in relationships is an important factor for empathy growth. One can create empathic understanding only through personal experience and knowledge of a particular problem in real experience. Based on the well-managed practical experience during the Effective Practice, and on personal experience with others, it is possible to reconsider our own feelings and achieve a change of attitude and life perspective.

In this respect, organizing of Effective Student Practices has significant importance not only in terms of education, but also in terms of forming mature people who will be ready to help in their profession.

\section{Conclusion}

Effective Practices focused on counseling of families going through specific stressful situations presumes that the participants will learn and/or improve counseling skills. Their preparation is made up of two levels: The first level consists of personal growth of students; it merges with, as well as further develops in the second level. The central objective of this second level is to create a space for formation meetings of people who will become their clients and will need their help. Practicing such assistance in an atmosphere of security, support and mutual trust creates space for better understanding of the problem as well as a platform for creation of greater awareness about themselves; about their own character, strengths 
and weaknesses of their personality; desires; needs; last but not least, skills. At the same time, they strengthen their cognitive, relational and emotional skills, as well as capability of internal resources self-updating.

\section{References}

1. TREBSKI K (2016) Counselling as a Helping Relationship and Pastoral Counselling Trnava: Good Book. Project outcome: A New Model of Effective Student Practices Using Counselling in Families with Specific
Social Problems], KEGA No. 010TTU4/2014.

2. BREAKWELL GM, SMITH JA, WRIGHT DB (2012) eds., Research Methods in Psychology: $4^{\text {th }}$ edition. Sage.

3. BINAROVA M, SOBOTKOVA I (2007) Life Satisfaction and Functioning of Families with Physically Disabled Child. In: Psychology and child psychopsychology. 42, No. 4

4. HILL at al. (2005) Consensual Qualitative Research: An Update. In: Journal of Counseling Psychology, Vol 52(2), 196-205. 